\title{
Le virus West Nile
}

\section{La conquête de l'Ouest}

Marion C. Lanteri, Azzedine Assal, Philip J. Norris, Michael P. Busch

> Le virus West Nile (WNV) ou virus du Nil occidental fait parler de lui depuis les années 1990 par les épidémies qu'il a provoquées autour du bassin méditerranéen et en Europe centrale. Depuis son apparition en 1999 en Amérique du Nord, le WNV est devenu la principale cause d'encéphalites arbovirales aux États-Unis. II s'est répandu au cours des dix dernières années sur l'ensemble du continent nord-américain. La sévérité des symptômes observés et la transmission du virus lors de transfusions sanguines et de transplantations d'organes ont nécessité la mise en place de tests de dépistage, de réseaux de surveillance et d'études pour mieux comprendre l'écologie, l'épidémiologie et la biologie de cet agent pathogène. $\varepsilon$ E Europe, les épidémies ont été plus limitées, mais leur récurrence dans certaines régions est préoccupante. Une collaboration internationale s'est organisée pour éviter la transmission de ce flavivirus émergent et pour comprendre sa biologie afin de développer de futurs traitements. <

\section{Historique des épidémies}

Le virus West Nile (WNV) ou du Nil occidental est identifié pour la première fois en 1937 en Ouganda. II est présent depuis les années 1950 en Égypte [1] où la population du sud du pays a été rapidement infectée et où $50 \%$ des enfants de plus de 4 ans et $90 \%$ des adultes de plus de 20 ans possèdent des anticorps contre le virus [2]. À la même époque, le virus circule également en Israël suivant les mêmes cycles saisonniers [3]. Le WNV est détecté dans les années 1960 en France dans le delta du Rhône [4] et en Russie dans le delta de la Volga [5]. En 1974, la première épidémie d'importance chez l'homme survient en Afrique du Sud [6].

Le WNV a attiré l'attention de la communauté scientifique à partir de la fin des années 1990 en raison de neuf épidémies au cours desquelles des cas humains et/ou équins d'une sévérité inhabituelle ont été constatés

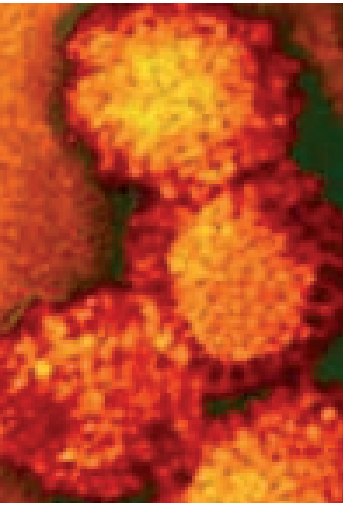

M. Lanteri, M. Busch, P. Norris :

Blood Systems Research

Institute, UCSF Department

of Laboratory Medicine,

270 Masonic avenue,

94118 San Francisco, États-Unis.

A. Assal:

Établissement français du sang, 20, avenue du Stade de France, 93218 La Plaine Saint-Denis Cedex, France.

marionlanteri@yahoo.fr

dans les pays du pourtour méditerranéen comme l'Algérie, le Maroc, la Tunisie, l'Italie, la France, en plus d'Israël et des pays d'Europe centrale et de l'Ouest comme la Roumanie et la Russie [7]. Mais ce n'est qu'au début des années 2000, avec son introduction sur le continent américain, que le WNV révèle son potentiel épidémique [8]. En Europe, la récurrence des épidémies dans certaines régions suggère l'implantation du virus dans l'environnement et impose une surveillance pour évaluer le risque épidémique [5].

\section{Considérations écologiques}

Le WNV est un arbovirus endémique dans certaines régions d'Afrique, d'Océanie et d'Asie, ré-émergent dans certaines régions d'Europe, et émergent sur le continent américain. Pour se propager, le virus a besoin de conditions écologiques facilitant la rencontre entre le réservoir viral et le vecteur. Ce cycle de transmission est le plus souvent rural et silencieux jusqu'à ce que le virus soit transmis a un hôte développant des symptômes visibles (voir la physiopathologie

$(\rightarrow)$ Voir l'article de M.C. Lanteri et al., page 382 de ce numéro dans $[46])(\rightarrow)$.

\section{Le vecteur}

Deux notions doivent être distinguées: (1) la compétence vectorielle qui traduit la possibilité qu'un arthropode transmette un virus, et (2) la capacité vectorielle qui reflète l'efficacité de la transmission du virus. Un vecteur compétent peut transmettre le virus après avoir ingéré du sang contaminé prélevé sur un réservoir/hôte animal infecté dans la nature. Le virus se multiplie et transite vers les glandes salivaires de l'arthropode qui peut alors le transmettre à un hôte naïf. La capacité vectorielle dépend de facteurs liés au vecteur (densité de population, durée du cycle extrinsèque, agressivité), à l'environnement (climat, photopériode) et à la population sensible. 
Pendant les épidémies des années 1990, les moustiques Culex pipiens ont été les principaux vecteurs du virus en Europe et aux États-Unis. Sur le continent nord-américain, les vecteurs les plus compétents sont les moustiques Culex pipiens, Culex quinquefasciatus et Culex tarsalis [9]. Les modes de vie et de reproduction des moustiques varient selon l'espèce : distribution spatiotemporelle, habitudes nutritives, habitudes de ponte, qualité des eaux dans lesquelles ils prolifèrent, étendue de la zone d'habitat. La prise en compte de ces différences est importante lors du développement de modèles prédictifs de l'abondance des moustiques en fonction des conditions climatiques afin de mieux lutter contre le vecteur [10].

\section{Le réservoir}

Le WNV a été isolé à partir de 198 espèces d'oiseaux impliquées dans la propagation du virus avec des rôles et sensibilités variés [11]. Les oiseaux servent de réservoirs et d'amplificateurs du virus et développent de forts titres viraux après inoculation du virus. Une forte mortalité des oiseaux a été observée lors des épidémies de 1998 et 2000 en Israël [12], et en Amérique du Nord au cours des dix dernières années avec des épizooties d'une ampleur jusque-là inégalée. Certaines espèces d'oiseaux telles que les corvidés (corbeaux, corneilles, pies, témias et geais) sont utilisées comme des indicateurs naturels de la présence du virus dans la nature.

\section{Phylogénie virale et répartition géographique}

Des études phylogénétiques réalisées sur la région du génome codant la protéine d'enveloppe $(\varepsilon)$ ont montré que les souches de virus West Nile isolées dans différentes régions du monde se repartissent selon cinq lignages. Les souches virales qui constituent le lignage 1 proviennent d'Afrique de l'Ouest, du Moyen-Orient, d'Europe de l'Est, d'Amérique du Nord et d'Australie, alors que celles du lignage 2 proviennent d'Afrique sub-saharienne et de Madagascar [13] et ont récemment émergé en Europe de l'Est [14]. Les souches Rabensburg présentes en République Tchèque et en Autriche constituent le lignage 3 ; la souche LEIV-98 isolée en Russie à partir d'une tique constitue le lignage 4, et les souches d'Inde le lignage 5 [15].

Parmi les virus du lignage 1 , on distingue deux clades (ou groupes phylogénétiques) et plusieurs clusters de virus.

- Le clade la comprend le cluster des virus responsables des épidémies les plus récentes en Israël et en Amérique du Nord, le cluster des souches ayant circulé en Europe et Russie dans les années 1990 [16], le cluster des deux souches responsables des épidémies en Italie en 1998 et 2008 [17], ainsi que les clusters des souches de la République Centrafricaine dans les années 1980 et d'Égypte dans les années 1950 [13].

- Le clade lb (virus Kunjin) est restreint géographiquement et uniquement présent en Australie [18].

Les souches de WNV responsables des épidémies en Amérique du Nord depuis 1999 sont identiques à 99,7\% aux souches virales recensées en Israël et sont regroupées dans un sous-clade du clade la suggérant que le WNV ayant émergé aux États-Unis en 1999 provenait du MoyenOrient [19].
La répartition géographique des souches virales et la cocirculation de souches variées dans certaines régions comme en Italie [20] ou en Israël [21] conforte I'hypothèse selon laquelle les oiseaux migrateurs véhiculeraient les souches virales le long de leurs couloirs de migration (Figure $1 \mathrm{~A}$ ) et seraient responsables de l'introduction ou de la réintroduction du virus dans différentes zones géographiques au gré de leurs cycles migratoires (Figure lA). Au cours des vingt dernières années, le nombre d'épidémies causées par des souches virales appartenant au lignage 1 montrent que le virus circule et rencontre en Europe des conditions favorables à son introduction et à son maintien comme les études de séroprévalence l'ont montré en Italie [20].

\section{Émergence du virus West Nile sur le continent américain : nouvelles caractéristiques}

Les événements ayant permis l'introduction du WNV sur le continent nord-américain restent inconnus. Depuis son introduction dans l'état de New York en 1999, le WNV est devenu la première cause d'encéphalite arbovirale aux États-Unis [22]. Les problèmes de santé publique associés à son introduction ont obligé la communauté scientifique et les pouvoirs publics à développer rapidement des réseaux de surveillance, des campagnes de prévention, des tests de dépistage pour éviter sa transmission par transfusion sanguine ou greffe d'organes, des stratégies économiques pour limiter les coûts associés, ainsi que la recherche de solutions prophylactiques.

\section{Nouvelles considérations écologiques}

En Europe, jusqu'aux années 1990, WNV ne semblait pas se maintenir dans l'environnement. Cette tendance s'est inversée pendant les vingt dernières années avec une récurrence des épidémies dans certaines régions et un maintien du cycle de transmission entre espèces de moustiques et d'oiseaux locaux en dehors des périodes épidémiques, suggérant un passage du virus à l'endémicité [8] (Figure IB et IC). En Amérique du Nord, le virus a trouvé des conditions favorables à son implantation et à son maintien et il s'est déplacé sur de vastes distances [8] (Figure 1B).

Plusieurs hypothèses sont à retenir : (1) les oiseaux du Nouveau Monde n'ayant pas coévolué avec le WNV, ils n'ont pas développé les mêmes caractéristiques que ceux de l'Ancien Monde et ont facilité la transmission du virus (exemple : le développement de charges virales plus élevées) [23] ; (2) le virus a gagné en capacité réplicative, résistance et virulence au contact de nouvelles espèces de moustiques et d'oiseaux (WN02 remplaçant WNVNY99) 
A
B

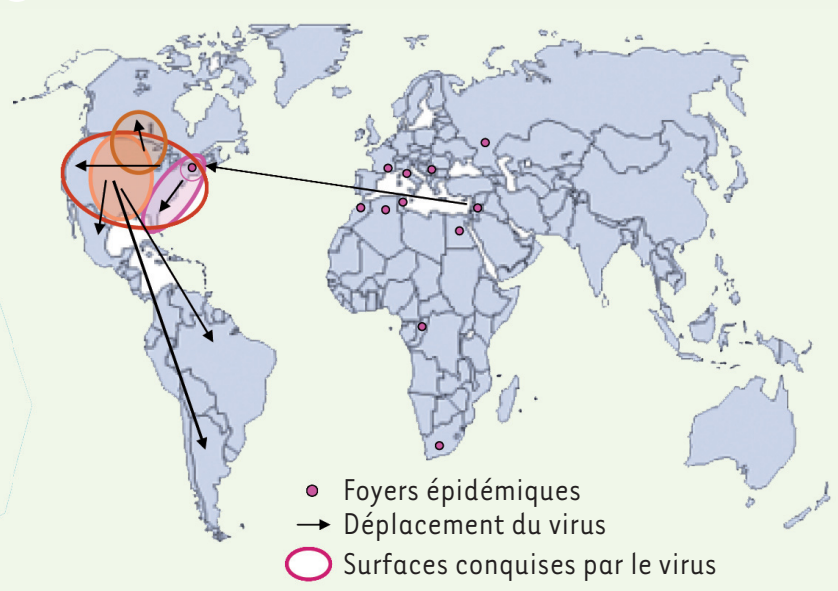

Ancien Monde

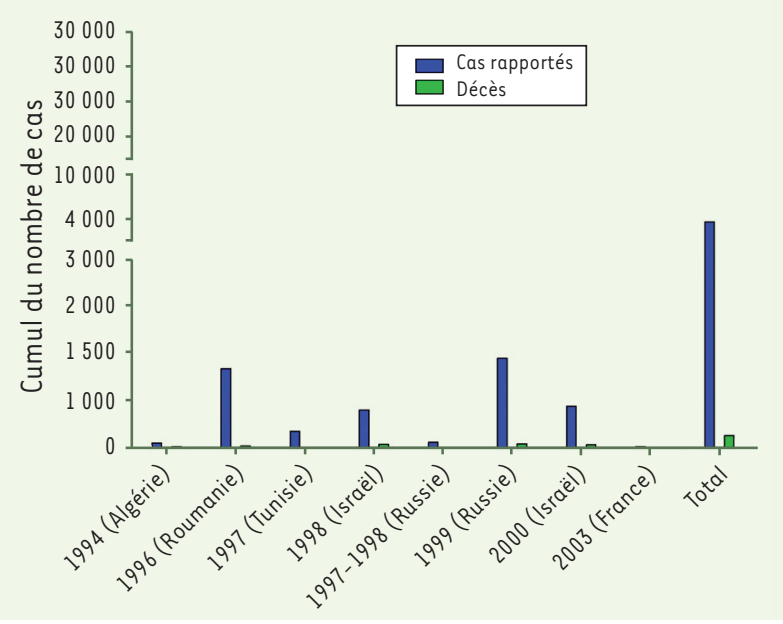

Figure 1. Distribution géographique du virus West Nile. A. Organisation des couloirs migratoires à la surface du globe. Les surfaces colorées représentent chacune un couloir migratoire. Les mouvements se font au sein de ces couloirs migratoires selon un axe nord-sud [40]. B. Répartition et déplacement des foyers épidémiques de virus West Nile de l’Ancien Monde vers le Nouveau Monde et colonisation du continent américain. C. Cumul du nombre de cas humains d'infection par le virus West Nile dans l'Ancien Monde (partie droite) et dans le Nouveau Monde (partie gauche) au cours des vingt dernières années $[7,25,38,41-43]$.

[8] ; (3) le virus est maintenu dans l'environnement par des moustiques qui survivent à l'hiver ou dans les œufs en diapause, contaminés par transmission transovarienne [24].

\section{Sévérité des manifestations cliniques}

Le WNV fut isolé pour la première fois en Ouganda en 1937 du sang d'une femme souffrant de fièvre. Dans les années 1950 en Égypte, la population, rapidement immunisée, ne développait que des symptômes mineurs [1]. Par conséquent, l'étude de ce virus a suscité peu d'intérêt. Les épidémies des années 1990 ont montré cependant que certaines souches virales du lignage 1 gagnaient en virulence au contact de populations naïves et causaient un nombre plus important d'encéphalites, de méningites et de morts chez l'homme et le cheval [25] (Figure 1C).
L'épidémie de 1999 dans l'État de New York se caractérisa par l'hospitalisation d'un nombre important de patients présentant des symptômes neurologiques graves [22]. Alors que pendant les dix années ayant précédé l'introduction du WNV aux États-Unis, seulement 10 cas d'encéphalite et 172 cas de méningite non bactériennes avaient été recensés par le département de la santé de la ville de New York, ce même département a enregistré 650 suspicions de méningites ou d'encéphalites virales au cours de l'année 1999 [22]. Dans les années qui suivirent, le nombre de patients de tous âges porteurs de symptômes neurologiques ne fit qu'augmenter et se déplacer d'Est en Ouest au fur et à mesure de la propagation du virus dans l'environnement [26]. 
L'infection par le WNV est asymptomatique dans $80 \%$ des cas. Environ $20 \%$ des infections s'expriment de façon paucisymptomatique par un syndrome pseudogrippal (fièvre, maux de tête, fatigue, éruption cutanée) ; moins de $1 \%$ des infections touchent le système nerveux (encéphalite, méningite, perte de mémoire, paralysie). Les enfants, personnes âgées et sujets immunodéprimés semblent développer des symptômes plus graves [27]. Les critères utilisés pour le diagnostic d'une infection par le WNV sont définis par la combinaison de symptômes cliniques et de paramètres biologiques (présence d'anticorps spécifiques, détection et isolement viral) [22].

En l'absence de traitement spécifique et de vaccin, il est important de surveiller la circulation du virus dans l'environnement afin de prendre des mesures préventives qui protègent les populations à risque. Même si l'homme ne développe pas de titres viraux assez importants pour transmettre le virus au moustique, la transmission d'homme à homme peut se faire par transfusion sanguine [28] ou greffe d'organes [29].

\section{Transmission du virus par transfusion sanguine et greffe d'organes/tissus}

Une conséquence inattendue de la rapide extension de l'épidémie de WNV aux États-Unis a été la mise en évidence de nouveaux modes de transmission du virus par la transfusion sanguine et la greffe d'organes et de tissus. Dans ces contextes particuliers, l'incidence des formes neurologiques et le taux de mortalité sont rapidement apparus significativement plus élevés que lors d'une transmission vectorielle du virus [30]. Ce tournant dans l'épidémiologie du WNV a imposé la mise au point de techniques fiables de diagnostic moléculaire dans les plus brefs délais [31].

Chez les sujets symptomatiques suspects d'une infection par WNV, le diagnostic repose principalement sur la mise en évidence par des méthodes ELISA d'anticorps dirigés contre le virus. Une sérologie positive nécessite cependant la mise en œuvre d'une méthode de confirmation en raison de réactions croisées avec d'autres flavivirus comme ceux qui sont responsables de la dengue ou de l'encéphalite de Saint-Louis. La technique de confirmation de référence est la mise en évidence d'anticorps neutralisants par réduction de plages de lyses. La détection du virus par RT-PCR ou en culture cellulaire [31] ou celle d'antigènes viraux en ELISA est possible mais ces techniques sont peu sensibles en raison de la brièveté de la virémie et de la virorachie ${ }^{1}$. Les antigènes viraux sont parfois détectables par des techniques immunohistochimiques sur des nécropsies.

\section{Mise en place de réseaux de surveillance : la situation aux États-Unis}

Tout cas de WNV doit être rapporté au Center for disease control and prevention (CDC) par voie électronique via le réseau de surveillance ArboNET qui a comptabilisé, depuis 1999, 30302 cas de West Nile dont 12489 cas neurologiques et 1178 décès (Figure 1C). Depuis 2002, un

\footnotetext{
${ }^{1}$ La virorachie est la présence de virus dans le liquide céphalorachidien.
}

système équivalent existe au Canada avec le réseau de surveillance MONITOR qui a comptabilisé 4559 cas rapportés. Après son entrée dans l'État de New York, le virus s'est déplacé d'est en ouest aux États-Unis et a rapidement atteint le Canada et le Mexique. Le virus a infecté des oiseaux locaux et migrateurs qui sont probablement responsables de son entrée en Amérique centrale et en Amérique du Sud [32] (Figure 1A).

D'après les données collectées aux États-Unis par Arbo$N \varepsilon T$, l'épidémie a atteint son niveau le plus élevé en 2002 et la stabilité du nombre de cas depuis 2004 suggère que le WNV est maintenant endémique (Figure 1C).

\section{Réaction face au risque de transmission} par transfusion sanguine et greffe d'organes

Chaque année, plus de 4,5 millions de patients aux États-Unis, et environ 50 millions de patients dans le monde, ont besoin d'être transfusés. Lorsqu'en 2002-2003 les premiers cas de transmission du WNV par transfusion sanguine ont été documentés, la communauté des établissements du sang a jugé nécessaire d'instaurer de nouveaux tests de dépistage pour rechercher la présence du WNV dans le sang collecté aux États-Unis et au Canada [33] (Figure 2A). En partenariat avec la communauté scientifique et industrielle, de nouveaux tests de dépistage basés sur la détection du génome viral ont été optimisés et utilisés à partir de l'été 2003 [34]. La stratégie de dépistage a évolué au cours du temps mais en règle générale, les échantillons sont testés en groupe ( 6 ou 16 selon le test utilisé). $\varepsilon n$ cas de réactivité du groupe, chaque échantillon est testé une seconde fois de façon individuelle [35] (Figure $2 B$ ). L'implémentation de cette stratégie de dépistage entraîna une diminution du nombre de cas de transmission du WNV par transfusion, mais plusieurs cas de transmissions furent néanmoins documentés au cours des années qui suivirent (Figure 2A). La stratégie de dépistage fut modifiée pour tester chaque échantillon de façon individuelle en saison épidémique [36] (Figure 2B). Des études épidémiologiques, virologiques et immunologiques ont été menées et sont poursuivies pour mieux comprendre et prévenir la transmission de ce virus et développer des outils de diagnostic et de dépistage adaptés (Figure $2 \mathrm{C}$ ).

\section{Situation en France}

Le WNV a été formellement identifié dans les pays du pourtour méditerranéen au début des années 1950 lors d'une épidémie survenue en Égypte. Les recherches rétrospectives permettent de penser que des formes neurologiques de l'infection équine, répertoriées sous 


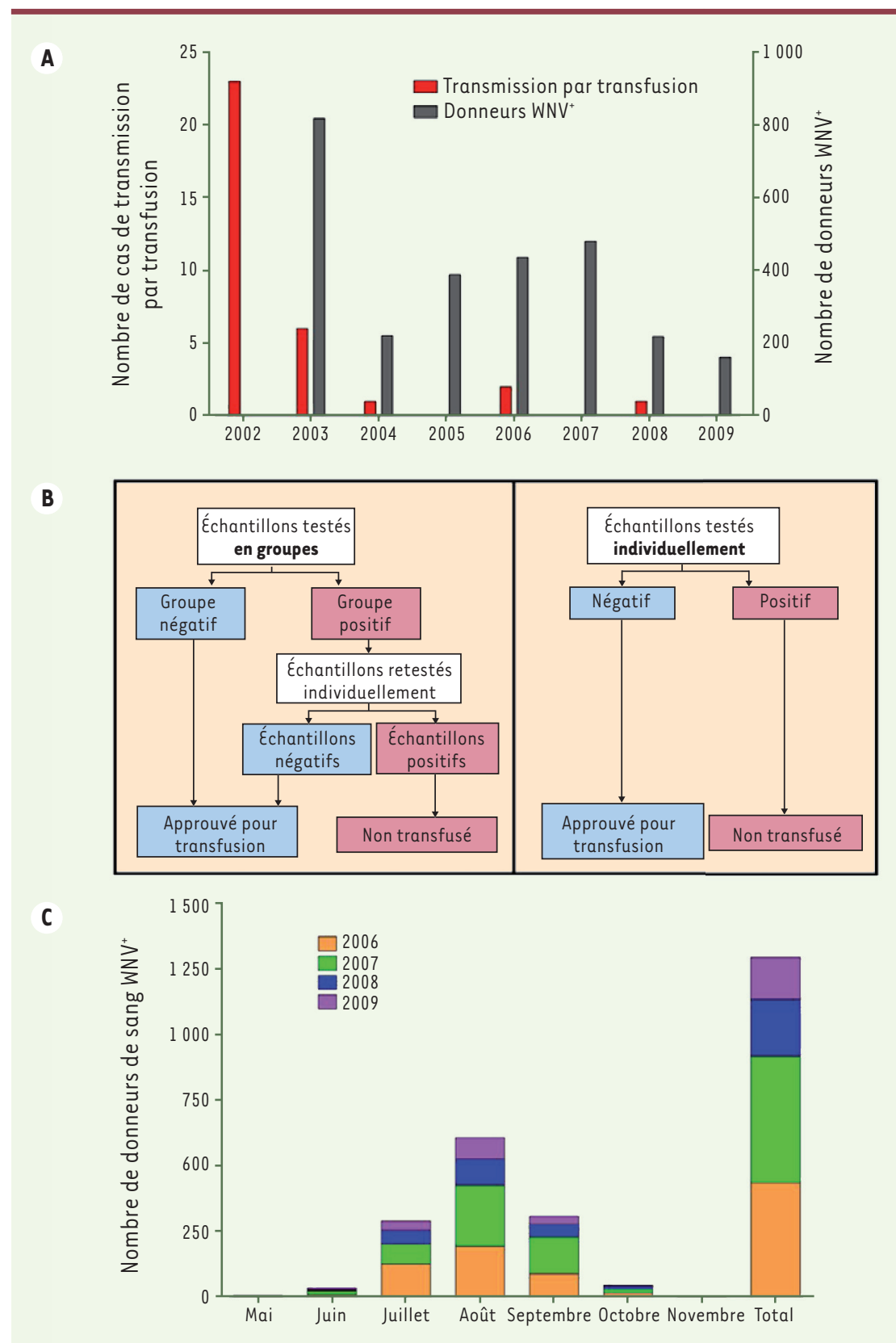

Figure 2. Données épidémiologiques. $A$. Nombre de cas de transmission du virus West Nile par transfusion et nombre de donneurs de sang dépistés positifs pour le virus West Nile après que le test de dépistage a été implémenté [44]. B. Stratégie mise en place pour tester le sang de façon groupée en mélangeant des échantillons provenant de 6 ou 16 donneurs (selon le test utilisé) et en testant une seconde fois de façon individuelle les échantillons du groupe réactif pour exclure les unités contaminées. À la première réactivité confirmée, on passe d'un dépistage groupé à un dépistage individuel pour le reste de la saison épidémique [45]. C. Répartition du nombre de donneurs positifs pour le virus West Nile en fonction des mois de l'année pour la période 2006-2009 [44].

(1,42\% versus $0,18 \%$ ) [37]. En 2003, 7 cas humains confirmés et 4 cas équins ont été signalés dans le département du Var [38]. En 2004, 32 cas équins confirmés ont été diagnostiqués en Camargue dans la région des Saintes-Maries-de-la-Mer avec une mortalité de $22 \%$. Enfin en 2006, la circulation du WNV s'est manifestée par 5 cas équins dans la région d'Argelès-sur-Mer dans les Pyrénées-Orientales.

En somme, au cours des années 2000 , la présence du WNV dans les départements du pourtour méditerranéen s'est caractérisée par: (1) des cas groupés toujours très localisés ; (2) une absence de lien entre la survenue d'infections équines et d'infections humaines; (3) la mise en évidence de la circulation virale en fin de période estivale ; et (4) l'identification de foyers de transmission du WNV en dehors de la

l'appellation « lourdige », auraient été diagnostiquées en Camargue au cours du XIX $x^{\mathrm{e}}$ siècle.

Jusqu'à la fin des années 1990, peu de cas de WNV survenus en France ont été décrits dans la littérature. En 2000, une épizootie équine s'est déclarée dans la région de la petite Camargue, avec une mortalité de $28 \%$ parmi les 76 cas équins confirmés. À l'issue de cette épizootie, les autorités sanitaires ont décidé de mettre en place un système de surveillance de l'infection WNV dans les départements exposés du pourtour méditerranéen. Une étude de séroprévalence fondée sur la détection des IgG spécifiques et réalisée en 2001 a démontré que la prévalence de porteurs d'anticorps anti-WNV était significativement plus élevée dans la population des donneurs de sang vivant dans la région de la Camargue que chez les donneurs de sang résidant à l'est de la ville de Marseille
Camargue (Var, Pyrénées-Orientales) entraînant une extension de la zone de surveillance du virus à l'ensemble des départements de la frange littorale et à la Corse.

Depuis 2001, un système de surveillance de l'infection WNV est mis en œuvre entre le $1^{\text {er }}$ juin et le 30 octobre. II s'agit d'une veille multi-espèces associant quatre volets : équin, aviaire, entomologique et humain [39]. Pendant la période de surveillance, tout adulte (plus de 15 ans) fébrile (température supérieure à $38,5^{\circ} \mathrm{C}$ ), hospitalisé pour une symptomatologie neurologique et chez lequel une ponction lombaire a montré un liquide céphalo-rachidien clair est considéré comme un cas suspect d'infection à WNV et fait l'objet d'une prise en charge diagnostique. 
Dès lors qu'un cas humain est confirmé, les autorités sanitaires réunissent une cellule de crise composée de différents experts afin de décider des mesures sanitaires à mettre en œuvre vis-à-vis des produits dérivés du corps humain (sang, greffons). Différents paramètres sont pris en compte : nombre et dispersion géographique des cas, abondance du vecteur, période de l'année, impact sur les stocks de produits sanguins.

Des mesures de prévention non spécifiques peuvent être rapidement mises en application. II s'agit en tout premier lieu d'interrompre la collecte de sang dans une zone potentiellement définie comme étant à risque par les experts, avec mise en quarantaine des produits collectés au préalable dans cette zone, dans l'attente de leur sécurisation par une recherche de l'ARN viral. II s'agit ensuite de procéder à l'exclusion temporaire (28 jours) des donneurs de sang vivant ou ayant séjourné dans la zone de circulation virale. Un rappel est réalisé auprès des médecins de collectes sur les symptômes cliniques de l'infection à évoquer lors de l'entretien pré-don et, parallèlement, les donneurs sont sensibilisés à l'information post-don en cas de survenue de signes cliniques évocateurs. Dans le cas où les mesures prises mettraient en difficulté l'approvisionnement en produits sanguins, le recours à un test de dépistage unitaire du génome viral pour les donneurs à risque peut être envisagé. Enfin, les procédés d'inactivation virale peuvent être mis en œuvre pour sécuriser les concentrés plaquettaires dont la péremption est courte.

À ce jour, en France, aucun cas de transmission inter-humaine de l'infection WNV par des produits d'origine humaine n'a été décrit. En France, les alertes liées à la circulation du WNV au cours de ces dernières années sont survenues au cours du mois de septembre et ont eu pour conséquence des annulations de collecte de sang, une exclusion temporaire de donneurs de sang et la sécurisation rétrospective du stock de produits sanguins collecté dans la zone à risque et non distribué au moment de l'alerte.

\section{Conclusion}

Le WNV a essentiellement fait parler de lui depuis son introduction aux États-Unis. Responsable d'épidémies récurrentes depuis 1999, le WNV est aussi devenu la première cause d'encéphalite arbovirale aux ÉtatsUnis. II s'est progressivement implanté sur l'ensemble du territoire ainsi que vers le nord au Canada, et vers le sud où sa présence a été signalée en Amérique centrale et en Amérique du Sud.

Le WNV constitue un modèle particulièrement intéressant d'émergence virale qui a été bien étudié au cours des dix dernières années. Non seulement des mesures préventives et de surveillance ont été mises en place mais des outils diagnostiques ont également été développés. Les solutions thérapeutiques sont toujours limitées et les solutions prophylactiques, bien qu'existant pour les chevaux, sont toujours en cours de développement pour l'homme. En Europe, le WNV, bien qu'en circulation dans l'environnement, n'est responsable que d'épidémies très localisées. Le WNV est présent en France où il circule dans les départements du Sud-Est. Le virus est sous surveillance et des cellules de crise sont d'ores et déjà en place pour gérer l'éventualité d'une épidémie de plus grande ampleur. $\diamond$

\section{SUMMARY}

West Nile virus. I. Conquest of the West

West Nile virus, a flavivirus discovered in 1937, attracted the attention of the scientific community in the late nineties with outbreaks, mostly in the Mediterranean and Central European countries. Since its emergence in 1999 in North America, WNV has become the leading cause of arboviral encephalitis in the US. Cycling between birds and mosquitoes, WNV was able to adapt to new species and expanded dramatically over the past 10 years. The severity of the symptoms reported and its transmission through blood transfusion and organ transplantation required the implementation of screening assays, surveillance networks, and ongoing studies to better understand its ecology, epidemiology, and biology. The situation in Europe is slightly different as only limited outbreaks have occurred so far, but the recurrence of those in certain areas raises concerns over the preparedness to limit the epidemic transmission and emergence in new European countries. WNV is present in both the New World and the Old World, and its recurrent outbreaks highlight the need for international cooperation and surveillance both to prevent its transmission and to develop therapeutic solutions. $\diamond$

\section{CONFLIT D'INTÉRÊTS}

Les auteurs déclarent n'avoir aucun conflit d'intérêts concernant les données publiées dans cet article.

\section{RÉFÉRENCES}

1. Taylor RM, Hurlbut HS, Dressler HR, et al. Isolation of West Nile virus from Culex mosquitoes. J Egypt Med Assoc $1953 ; 36: 199-208$.

2. Hurlbut HS, Rizk F, Taylor RM, Work TH. A study of the ecology of West Nile virus in Egypt. Am J Trop Med Hyg 1956 ; 5 : 579-620.

3. Bernkopf H, Levine $\mathrm{S}$, Nerson R. Isolation of West Nile virus in Israel. J Infect Dis $1953 ; 93: 207-18$.

4. Joubert L, Oudar J, Hannoun C, et al. Épidémiologie du virus West Nile : étude d'un foyer en Camargue. IV. La méningo-encéphalomyélite du cheval. Ann Inst Pasteur (Paris) $1970 ; 118: 239-47$.

5. Platonov AE. West Nile encephalitis in Russia 1999-2001: were we ready? Are we ready? Ann NY Acad Sci $2001 ; 951$ : 102-16.

6. Jupp PG. The ecology of West Nile virus in South Africa and the occurrence of outbreaks in humans. Ann NY Acad Sci 2001 ; 951 : 143-52.

7. Murgue B, Murri S, Triki H, et al. West Nile in the Mediterranean basin: 1950 2000. Ann NY Acad Sci $2001 ; 951: 117-26$

8. Randolph SE, Rogers DJ. The arrival, establishment and spread of exotic diseases: patterns and predictions. Nat Rev Microbiol $2010 ; 8: 361-71$.

9. Hayes EB, Komar N, Nasci RS, et al. Epidemiology and transmission dynamics of West Nile virus disease. Emerg Infect Dis 2005 ; 11 : 1167-73.

10. Trawinski PR, Mackay DS. Meteorologically conditioned time-series predictions of West Nile virus vector mosquitoes. Vector Borne Zoonotic Dis $2008 ; 8: 505-21$.

11. Komar $\mathrm{N}$, Langevin $\mathrm{S}$, Hinten $\mathrm{S}$, et al. Experimental infection of North American birds with the New York 1999 strain of West Nile virus. Emerg Infect Dis $2003 ; 9: 311-22$

12. Malkinson $M$, Banet $C$, Weisman $Y$, et al. Introduction of West Nile virus in the Middle East by migrating white storks. Emerg Infect Dis $2002 ; 8: 392-7$.

13. Monini M, Falcone $\varepsilon$, Busani L, et al. West Nile virus: characteristics of an African virus adapting to the third millennium world. Open Virol J $2010 ; 4$ : 42-51. 


\section{RÉFÉRENCES}

14. Bakonyi T, Ivanics $\varepsilon$, Erdelyi K, et al. Lineage 1 and 2 strains of encephalitic West Nile virus, central Europe. Emerg Infect Dis $2006 ; 12: 618-23$.

15. Lanciotti RS, Ebel GD, Deubel V, et al. Complete genome sequences and phylogenetic analysis of West Nile virus strains isolated from the United States, Europe, and the Middle East. Virology $2002 ; 298: 96-105$.

16. Charrel RN, Brault AC, Gallian P, et al. Evolutionary relationship between Old World West Nile virus strains. Evidence for viral gene flow between Africa, the Middle East, and Europe. Virology 2003; $315: 381-8$.

17. Barzon L, Squarzon L, Cattai M, et al. West Nile virus infection in Veneto region, Italy, 2008-2009. Euro Surveill $2009 ; 14$.

18. Scherret JH, Poidinger M, Mackenzie JS, et al. The relationships between West Nile and Kunjin viruses. Emerg Infect Dis $2001 ; 7: 697-705$.

19. Lanciotti RS, Roehrig JT, Deubel V, et al. Origin of the West Nile virus responsible for an outbreak of encephalitis in the northeastern United States. Science $1999 ; 286: 2333-7$.

20. Calzolari M, Bonilauri P, Bellini R, et al. Arboviral survey of mosquitoes in two northern Italian regions in 2007 and 2008. Vector Borne Zoonotic Dis $2010 ; 10: 875-84$.

21. Bin H, Grossman Z, Pokamunski S, et al. West Nile fever in Israel 1999-2000: from geese to humans. Ann NY Acad Sci 2001 ; 951 : 127-42.

22. Asnis DS, Conetta R, Waldman G, Teixeira AA. The West Nile virus encephalitis outbreak in the United States (1999-2000): from Flushing, New York, to beyond its borders. Ann NY Acad Sci $2001 ; 951: 161-71$.

23. McLean RG, Ubico SR, Docherty DE, et al. West Nile virus transmission and ecology in birds. Ann Ny Acad Sci $2001 ; 951: 54-7$.

24. Kramer LD, Styer LM, Ebel GD. A global perspective on the epidemiology of West Nile virus. Annu Rev Entomol $2008 ; 53: 61-81$

25. Hayes CG. West Nile virus: Uganda, 1937, to New York City, 1999. Ann NY Acad Sci 2001 ; 951 : $25-37$.

26. Reimann CA, Hayes EB, DiGuiseppi C, et al. Epidemiology of neuro-invasive arboviral disease in the United States, 1999-2007. Am J Trop Med Hyg 2008 ; 79 : 974-9.

27. Hayes $\varepsilon B$, Gubler DJ. West Nile virus: epidemiology and clinical features of an emerging epidemic in the United States. Annu Rev Med 2006 ; 57 : 181-94.

28. Harrington $\mathrm{T}$, Kuehnert MJ, Kamel $\mathrm{H}$, et al. West Nile virus infection transmitted by blood transfusion. Transfusion 2003; $43: 1018-22$.

29. Iwamoto M, Jernigan DB, Guasch A, et al. Transmission of West Nile virus from an organ donor to four transplant recipients. $N$ Engl J Med $2003 ; 348: 2196-203$.

30. Kumar D, Humar A. Emerging viral infections in transplant recipients. Curr Opin Infect Dis 2005 ; $18: 337-41$

31. Lanciotti RS, Kerst AJ, Nasci RS, et al. Rapid detection of west Nile Virus from human clinical specimens, field-collected mosquitoes, and avian samples by a TaqMan reverse transcriptasePCR assay. J Clin Microbiol $2000 ; 38:$ 4066-71.

32. Morales MA, Barrandeguy M, Fabbri C, et al. West Nile virus isolation from equines in Argentina, 2006. Emerg Infect Dis $2006 ; 12: 1559-61$.

33. Busch MP, Caglioti S, Robertson EF, et al. Screening the blood supply for West Nile virus RNA by nucleic acid amplification testing. $N$ Engl J Med $2005 ; 353: 460-7$
34. Stramer SL, Custer B, Busch MP, Dodd RY. Strategies for testing blood donors for West Nile virus. Transfusion $2006 ; 46: 2036-7$.

35. Custer B, Tomasulo PA, Murphy EL, et al. Triggers for switching from minipoo testing by nucleic acid technology to individual-donation nucleic acid testing for West Nile virus: analysis of 2003 data to inform 2004 decision making. Transfusion $2004 ; 44: 1547-54$.

36. Biggerstaff BJ, Petersen LR. A modeling framework for evaluation and comparison of trigger strategies for switching from minipool to individualdonation testing for West Nile virus. Transfusion $2009 ; 49$ : 1151-9.

37. Charrel RN, de Lamballerie X, Durand JP, et al. Prevalence of antibody against West Nile virus in volunteer blood donors living in southeastern France. Transfusion $2001 ; 41$ : 1320-1.

38. Sanitaire Idv. Surveillance du virus West Nile en France 2003. http://www. invs.sante.fr/presse/2003/le_point_sur/west_nile_051103/

39. Gallian P, De Lamballerie X, De Micco P, Andreu G. West Nile virus (WNV): generalities and implications for blood transfusion. Transfus Clin Biol 2005 ; 12: 11-7.

40. Wikipedia. Carte du monde représentant les principales voies migratoires empruntées par les oiseaux. D'après D. Thompson et Byrkjedal, Shorebirds. Colin Baxter, 2001, 2007. Consultable sur : http://fr.wikipedia.org/wiki/ Fichier:Main_international_flyways_-_bird_migration-fr.svg.

41. CDC. West Nile virus activity - Human disease cases reported. Centers for Disease Control, 2005-2009. Consultable sur : http://www.cdc.gov/ncidod/ dvbid/westnile/surv\&control.htm.

42. Gubler DJ. Human arbovirus infections worldwide. Ann Ny Acad Sci 2001 ; $951: 13-24$.

43. MONITOR. Human West Nile Virus clinical cases and asymptomatic infections in Canada. 2002-2010. Consultable sur : http://www.eidgis.com/ wnvmonitorca/.

44. West Nile Virus Biovigilance Network. Consultable sur : http://www.aabb. org/programs/biovigilance/Pages/wnv.aspx.

45. Centers for Disease Control and Prevention (CDC). West Nile virus transmission via organ transplantation and blood transfusion: Louisiana, 2008. Morb Mortal Wkly Rep $2009 ; 58$ : 1263-7.

46. Lanteri MC, Diamond MS, Norris PJ, Busch MP. Infection par le virus West Nile chez I'homme. II. Aspects physiopathologiques et réponses immunitaires. Med Sci (Paris) $2011 ; 27: 382-6$

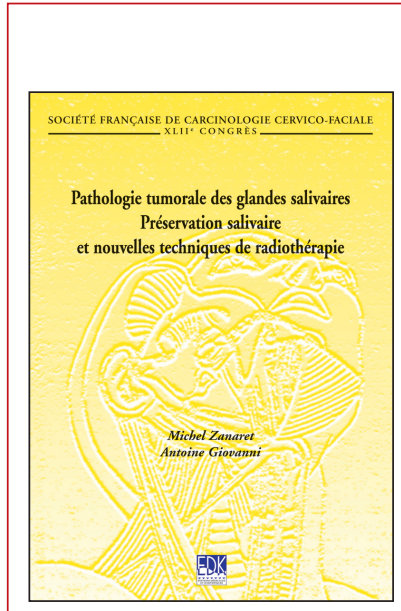

ISBN : 978-2-8425-4150-7 306 pages

\section{Bon de commande}

TIRÉS À PART

M.C. Lanteri

À retourner à EDK, 2, rue Troyon - 92316 Sèvres Cedex

Tél. : 0155641393 - Fax : 0155641394 - E-mail : edk@edk.fr

NOM :

Prénom :

Adresse :

Code postal :

Ville :

Pays :

Fonction :

Je souhaite recevoir l'ouvrage Pathologie tumorale des glandes salivaires : $35 €+3 €$ de port $=\mathbf{3 8} €$ TTC

en ............... exemplaire, soit un total de ................................. €

$\square$ Par chèque, à l'ordre de $\mathbf{E} \mathbf{D} \mathbf{K}$

$\square$ Par carte bancaire : $\quad \square$ Visa $\square$ Eurocard/Mastercard

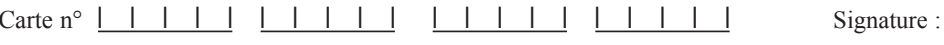

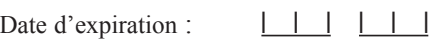

$\mathrm{N}^{\circ}$ de contrôle au dos de la carte : 